\title{
PROCEDENCIA DE UNA "EXIMENTE O DEFENSA DE CUMPLIMIENTO” DE LAS PERSONAS JURÍDICAS EN EL DERECHO ADMINISTRATIVO SANCIONADOR CHILENO
}

\author{
APPLICABILITY OF A CORPORATE "COMPLIANCE DEFENSE" IN \\ CHILEAN SANCTIONING ADMINISTRATIVE LAW
}

\author{
Héctor Hernández Basualto*
}

\begin{abstract}
RESUMEN: De la mano de los propósitos regulatorios de las sanciones administrativas contra las personas jurídicas y de la tendencia observable en el Derecho comparado, el artículo pretende demostrar que, en ausencia de regulación legal expresa sobre los presupuestos de la responsabilidad administrativa de las personas jurídicas, es posible interpretar el Derecho administrativo sancionador vigente en Chile en el sentido de que es procedente una eximente de responsabilidad consistente en el establecimiento de un modelo de cumplimiento adecuado para prevenir los hechos ilícitos cometidos por los empleados subalternos de la persona jurídica en el ejercicio de sus funciones.
\end{abstract}

Palabras clave: Compliance, eximente o defensa de cumplimiento, personas jurídicas, sanciones administrativas

\begin{abstract}
Taking into account the regulatory purposes of administrative sanctions against corporations and the observable trends in comparative law, the article aims to show that, in the absence of explicit statutory regulation on the administrative liability of corporations, there is a basis for interpreting Chilean sanctioning administrative law as granting corporations a defense based on the implementation of an adequate compliance model to prevent illicit acts committed by their low-level employees in exercise of their functions.
\end{abstract}

Keywords: Compliance, compliance defense, corporations, administrative sanctions

\section{EL PROBLEMA Y LA PROPUESTA}

Es usual en el Derecho chileno que los cuerpos legales que establecen infracciones y sanciones administrativas ${ }^{1}$ no expliciten los requisitos de la responsabilidad del infractor, al tiempo que tampoco existen reglas generales supletorias al respecto. Tratándose de la responsabilidad de personas naturales no es difícil, con todo, asumir que el requisito básico será la realización misma de (o al menos una intervención relevante en) la conducta infractora, de modo que la discusión puede centrarse en las exigencias subjetivas (¿responsabili-

Doctor en Derecho por la Universidad de Friburgo de Brisgovia. Profesor Titular de Derecho Penal de la Universidad Diego Portales. Dirección postal: Av. República 112, Santiago de Chile. Dirección electrónica: hector.hernandez@udp.cl

1 Por sanción "administrativa" se entiende en este trabajo toda sanción no impuesta por un tribunal con competencia penal, con independencia de si la impone un órgano administrativo o un tribunal; por infracción "administrativa", toda infracción que conduce a una sanción de ese tipo. 
dad objetiva, suficiencia de culpa, exigencia de dolo?). Tratándose en cambio de personas jurídicas, que por definición no actúan por sí mismas, de modo que en principio no es posible identificar un hecho genuinamente propio de ellas, la situación es mucho más grave, porque la ausencia de orientación legal permite prácticamente cualquier interpretación. Así, por ejemplo, si se adopta el proceder tradicional consistente en imputarle a la persona jurídica el hecho ilícito de determinadas personas naturales bajo determinadas circunstan$\operatorname{cias}^{2}$, podría interpretarse tanto que la persona jurídica solo responde por las infracciones dolosas de su representante legal que le reportan a ella un beneficio económico efectivo (una solución especialmente restrictiva), como que responde por cualquier infracción del último de sus empleados, con total independencia de las circunstancias del caso (una solución especialmente extensiva), entre múltiples otras interpretaciones intermedias imaginables.

Solo la jurisprudencia puede, entonces, fijar aquello que la ley ha dejado en la nebulosa. En este contexto se impone una discusión sobre los presupuestos racionales y justos de la aplicación de sanciones a la persona jurídica por los hechos ilícitos en que incurren sus empleados.

No es posible hacerse cargo aquí del conjunto de esa discusión, pero sí se puede postular al menos la improcedencia de una forma de responsabilidad de la persona jurídica por las infracciones cometidas en su seno que aquí llamaremos "automática”, es decir, de una responsabilidad que se satisfaga con la sola imputación del hecho de alguna persona natural a la persona jurídica y prescinda por completo de los esfuerzos desplegados en la organización subyacente por impedir tales infracciones ${ }^{3}$. Consecuentemente, se postula que el Derecho vigente en Chile permite eximir de responsabilidad administrativa a la persona jurídica

2 Una alternativa sería hacer responder sin más a la persona jurídica por un hecho reconocidamente ajeno, pero lo habitual tratándose de la imposición de sanciones es justificar una responsabilidad supuestamente "directa" mediante la imputación del hecho de un individuo (aunque no necesariamente identificado) a la persona jurídica, como si fuera un hecho propio (al menos también) de esta última. Los modelos en disputa en ese contexto, entre ellos las diversas variantes de la "teoría del órgano", se diferencian entre sí básicamente por la mayor o menor amplitud del círculo de sujetos cuyos hechos son imputables (solo los representantes, también otros directivos, cualquier empleado, etc.) y por las distintas exigencias que deben cumplir esos hechos para provocar tal efecto (dolo, culpa, carácter beneficioso del hecho para la empresa, etc.). Existe también la posibilidad teórica de fundar la responsabilidad de una persona jurídica en un output ilícito de la empresa sin referencia (al menos no necesaria) al hecho de alguna persona natural (sobre modelos de genuina responsabilidad "autónoma" u "originaria" como serían estos últimos y las dudas sobre la existencia de verdaderas consagraciones de ellos en el derecho [penal] comparado, Hernández [2010] p. 216 s. con nota al pie 43). Lo común a todas estas aproximaciones es que se centran o bien en el hecho de una persona natural o bien en el output originado en la empresa, sin requerir (al menos no necesariamente) algo más referido a la organización y al funcionamiento global de la persona jurídica. Una exigencia sistémica de este tipo es lo que se propone en el presente trabajo. Por cierto no es un modelo incompatible ni con alguna forma de imputación en sentido convencional (como se verá luego, es difícil imaginar que no se le termine imputando algo a la persona jurídica) ni con una responsabilidad autónoma u originaria, con tal que se considere esa exigencia adicional que es su nota distintiva y constituye el objeto de las páginas siguientes.

3 Deliberadamente no se habla aquí de "responsabilidad objetiva" porque, como se verá en el apartado siguiente, en rigor, desde la perspectiva del principio de culpabilidad en la forma en que este es entendido (al menos de modo abrumadoramente mayoritario) en Derecho penal, la rama jurídica en que tiene su origen, la responsabilidad de la persona jurídica es siempre objetiva. La cuestión aludida con el término es otra y concierne a si la responsabilidad exige algo más (estructural o sistémico) que el hecho de una persona natural. 
que demuestre haber desarrollado seria y consistentemente un sistema adecuado de prevención de actuaciones ilícitas en el seno de la organización empresarial, sistema que si bien pudo haber fracasado en el caso en cuestión, porque es imposible evitar absolutamente las actividades ilícitas en organizaciones complejas, permite ver dicho fracaso como un evento excepcional que no pone en duda la seriedad de los esfuerzos de prevención de la empresa. Esto es, que la existencia y suficiencia de tal sistema puede constituir una causa eximente de responsabilidad o, dicho en los términos más procesales de la tradición anglosajona, como una "defensa" capaz de exonerarla de responsabilidad. Se trataría de una eximente o defensa de compliance o cumplimiento.

Esta propuesta interpretativa descansa sobre dos premisas, una positiva y otra negativa. La primera, cuyo desarrollo constituye el núcleo de este trabajo, se refiere a la racionalidad y justicia de una eximente o defensa de este tipo. La segunda ya fue aludida y consiste en que es precisamente el silencio de la ley respecto de los requisitos de la responsabilidad lo que permite interpretarla de acuerdo con lo que se considere fundadamente como racional y justo. No hay, en general, razones de texto que se opongan a entender que la responsabilidad de la persona jurídica supone algo más que la sola comisión del hecho ilícito en su seno, concretamente que supone algún defecto más permanente o estructural que, a pesar de ser necesariamente imputable a quienes actúan por ella, le pueda ser reprochado a ella en cuanto tal. Sería arbitrario exigir texto legal expreso para darle cabida a una eximente o defensa de cumplimiento cuando no existe texto legal expreso que defina cuáles son los supuestos bajo los cuales la persona jurídica puede ser hecha responsable por lo que sus empleados hagan en el contexto de su desempeño en ella. Que en ausencia de reglas sobre el particular haya de regir precisamente un sistema de responsabilidad automática, sin mayores exigencias, carece de todo fundamento ${ }^{4}$.

\section{LAS RAZONES PARA EL RECONOCIMIENTO DE UNA EXIMENTE DE CUMPLIMIENTO}

El asunto se puede plantear al menos desde dos perspectivas distintas, una que considera que un modelo de responsabilidad automática amaga garantías fundamentales y otra que enfatiza el carácter irracional de una sanción impuesta a todo evento, esto es, al margen de cualquier consideración de los esfuerzos del sujeto sancionado. Ambas perspectivas cier-

Es dudoso que la propuesta de este trabajo sea un ejercicio de analogía in bonam partem, como podría pensarse a primera vista. No sería problemático asumirlo así si se considera que, al margen de cualquier discusión sobre la vigencia de alguna prohibición de analogía en el Derecho administrativo sancionador, en Derecho penal existe una tendencia favorable (aunque en ningún caso unánime) a esta forma de analogía [sobre esto en Chile Cury (2005) p. 200 ss.], la que en la llamada Parte general, en particular en la teoría de la infracción punible, parece ser sencillamente inevitable. Pero en rigor debe tenerse presente que, a diferencia de los casos usuales a propósito de los cuales se discute el asunto, en este caso lo único claro es el propósito legal de que se imponga una sanción, pero sin la más mínima indicación de los requisitos para ello, de modo que al respecto todas las soluciones imaginables son necesariamente analógicas o, peor aún, creaciones ex nibilo, sin que sea plausible sostener que de ahí se sigue la imposibilidad de aplicar la ley. En semejante contexto es difícil aceptar que la cuestión clasificatoria, de por sí dudosa, pueda ser decisiva en un sentido u otro. Por tal razón aquí se sostiene que la cuestión está abierta a la argumentación racional. 
tamente no son excluyentes y hasta pueden ser complementarias, pero por sus características propias merecen revisarse por separado.

\section{LA PERSPECTIVA GARANTISTA Y SUS LIMITACIONES}

Podría verse en un sistema de responsabilidad automática el compromiso de ciertas garantías que debería reconocer la legislación administrativa sancionadora. En concreto, se podría apreciar una vulneración del principio de culpabilidad, por cuanto la imposición de una sanción administrativa a una persona jurídica con absoluta prescindencia de los esfuerzos realizados en ella para evitar la ocurrencia de ese tipo de hechos no tendría como presupuesto un hecho susceptible de ser reprochado a la persona jurídica, que es precisamente lo que exige el principio de culpabilidad.

Por cierto esta afirmación sería irrefutable si se tratara de la imposición de una sanción penal a una persona natural, con la consecuencia de que habría de afirmarse también su incompatibilidad con el orden constitucional, en la medida en que, a pesar de su frágil anclaje en el texto de la Constitución chilena, existe amplio acuerdo en cuanto a que el principio de culpabilidad constituye una garantía constitucional del Derecho penal en Chi$1 e^{5}$. Sin embargo, que eso rija también en sede de sanciones administrativas o que rija, en cualquier sede, también para las personas jurídicas, dista mucho de ser evidente.

En favor de esta aproximación garantista se podrían hacer valer dos líneas argumentales levemente diferentes pero complementarias. Por una parte, aquella que, en parte sobre la base de ciertas afirmaciones generales del Tribunal Constitucional ${ }^{6}$, sostiene que las garantías del Derecho penal se han de aplicar también al ámbito de las sanciones administrativas $^{7}$, tesis que, como se sabe, goza de predicamento también en otros ordenamientos ${ }^{8}$.

\footnotetext{
La Constitución no contiene ninguna referencia expresa al principio de culpabilidad, sin perjuicio de lo cual la doctrina penal ha ensayado variadas líneas de argumentación para fundarlo, en términos similares a lo ocurrido en otros ordenamientos. Así, por ejemplo, se ha invocado la dignidad humana (Cousiño (1992) pp. 12 ss.; NÁQUIRA (1995) p. 189), o bien se ha argumentado a partir del principio de irretroactividad de la ley penal (RoDRíGuez Collao y De la Fuente (1989) pp. 131 y ss., 136). Con todo, la línea argumentativa más influyente ha sido la desarrollada a partir prohibición constitucional de presumir de derecho la responsabilidad penal (RoDRíGUEZ Collao y De la Fuente (1989) pp. 139 ss.; Cousiño (1992) Tomo III, p. 15; GuZmán Dalbora (1994) pp. 190 ss.; Cury (2005) pp. 388, 446 s.; menos categórico Mera (1998) pp. 114 s.; véase también KüNSEMÜller (2001) pp. 235 ss.; un juicio crítico del argumento pero favorable al reconocimiento del status constitucional del principio en Soto (1999) p. 242; y HernándeZ (2007) pp. 18 ss.). Lo ha confirmado, a propósito de los delitos calificados por el resultado, la R.O.L, E.H.S Y E.O., Y DE J.C.C.C. CON TRIBUNAL DE GARANTÍA DE SAN BERNARDO (2010) cc. $13^{\circ}, 16^{\circ}$ y $18^{\circ}$; antes, en obiter dictum, MAURICIO RAMÍREZ GODOY Y OTROS, EN RELACIÓN CON DIVERSAS CAUSAS SEGUIDAS ANTE EL SÉPTIMO JUZGADO DEL TRABAJO DE SANTIAGO (2007) cc. $41^{\circ}, 48^{\circ}$ y $50^{\circ}$.

6 Fundamentalmente desde CONTROL DE CONSTITUCIONALIDAD MODIFICACIÓN DE LEY $N^{\circ} 4.601$ (1996), que afirma la aplicación "por regla general” de las garantías penales al Derecho administrativo sancionador (c. $9^{\circ}$ ). Véase también IBEROAMERICANA DE ENERGÍA IBENER S.A. CON SUPERINTENDENCIA DE ELECTRICIDAD Y COMBUSTIBLES (2006), que lo hace "con matices" (c. 5o).

$7 \quad$ Así, entre otros, Aróstica (1987) pp. 78 ss.; Alcalde (2003) p. 230; Alcalde (2009) p. 803; AlCalde (2011) p. 75; Vergara (2004 a) pp. 323 ss.; Vergara (2004 b) p. 143; Ried (2005) pp. 38 ss.; Bermúdez (2014) pp. 343 ss.; Cordero Vega (2015) pp. 502 ss.; Cordero Quinzacara (2014) pp. 251 ss.; Valdés (2006) pp. 290 ss., 322 ss.

8 Es conocida, por ejemplo, la tendencia en ese sentido del Derecho español, véase al respecto HUERGO LORA (2007) pp. 377 ss.; contrario, pero con abundantes referencias a la tesis favorable a la vigencia del principio de culpabilidad en la materia, NiETO (2012) pp. 319 ss.
} 
Por la otra, aquella que entiende que las garantías penales reconocidas para las personas naturales deben regir también para las personas jurídicas ${ }^{9}$. Del cruce de ambas líneas podría resultar que las garantías penales que inequívocamente rigen para personas naturales deben regir también en materia administrativa sancionadora para las personas jurídicas.

Sin embargo, al margen de las objeciones generales que se pueden levantar contra ambas líneas argumentales, principalmente contra la segunda ${ }^{10}$, es imposible compartir una convicción fuerte sobre la vigencia del principio de culpabilidad respecto de las personas jurídicas, por razones estructurales derivadas de la naturaleza misma de tales personas. Dicha naturaleza condiciona el sentido que a su respecto puede tener aquello que se da en llamar principio de culpabilidad, no solo en el ámbito de las sanciones administrativas, supuesto que dicho principio también rigiera en este ámbito, sino también en el ámbito del Derecho penal, a pesar de que ahí dicha vigencia se reconoce sin discusión.

En la medida en que la persona jurídica no actúa por sí misma sino solo mediante sujetos que actúan por ella, su responsabilidad supone, forzosamente, que se le imputen hechos de terceros, lo que no cambia por la circunstancia de que tales terceros tengan un vínculo más o menos intenso con ella. Adicionalmente, las razones por las cuales se le imputan tales hechos tampoco tienen que ver con algo que ella haya hecho, por la misma razón estructural ya mencionada (ella no hace nada, nunca). Esto marca una diferencia fundamental con los supuestos en que el comportamiento de otro se le imputa a una persona natural, pues, a menos que se esté en un régimen de responsabilidad objetiva, en general siempre se exige para dicha imputación una razón plausible basada en el propio comportamiento del sujeto a quien se le imputa la conducta del otro, como es el caso, por ejemplo, cuando se debe responder en razón de no haberlo controlado o vigilado adecuadamente teniendo el deber de hacerlo o cuando de algún modo se ha contribuido activamente al hecho. En cambio, cuando se dice, por ejemplo, que la persona jurídica responde por el hecho de su empleado porque no lo ha vigilado como es debido o porque se ha organizado de un modo tal que facilitó que el hecho tuviera lugar, en rigor se le está imputando el hecho de ese empleado en razón, a su vez, del hecho de otro empleado, aquel llamado a vigilar al anterior o responsable por la organización de la empresa. Desde esa perspectiva la responsabilidad de la persona jurídica es, en último término y necesariamente, siempre "responsabilidad objetiva"11.

De este modo, aunque se llegue a aceptar que el principio de culpabilidad tiene vigencia también en el ámbito de las sanciones administrativas y que las garantías penales que rigen para las personas naturales, entre ellas el principio de culpabilidad, rigen también

\footnotetext{
$9 \quad$ Más que afirmaciones generales, la tendencia se aprecia en el tratamiento de cuestiones específicas, como por ejemplo, la vigencia de ciertas garantías procesales. Así, por ejemplo, KöcK (2004) pp. 274 ss.

10 Que las garantías fundamentales rigen solo parcialmente y bajo importantes reservas y adaptaciones respecto de las personas jurídicas es algo pacífico. En Chile, por todos, Aldunate (2008) pp. 157 s. Lo ha reconocido el Tribunal Constitucional en EMPRESAS ARIZTÍA S.A. EN LA CAUSA SEGUIDA ANTE EL TRIBUNAL DE DEFENSA DE LA LIBRE COMPETENCIA (2013), a propósito del derecho a no declarar bajo juramento en causa propia (cc. $21^{\circ}$ a $23^{\circ}$ ). Véase también HERNÁNDEZ (2015) pp. 238 ss.

11 Lo hacen presente, por ejemplo, Schünemann (1995) p. 588; Feijóo SÁnchez (2002) p. 228; o Frisch (2013) pp. 832 ss.
} 
para las personas jurídicas, es indudable que el contenido y los alcances de este principio respecto de personas jurídicas han de ser necesariamente muy distintos de los que se le reconocen a dicho principio en relación con las personas naturales. Esta sola circunstancia sugiere la conveniencia de tomar cierta distancia de una aproximación basada exclusiva o siquiera preferentemente en el postulado de la vigencia de una garantía fundamental en favor de las personas jurídicas. No porque, a pesar del carácter manifiestamente más problemático de la asunción de tal garantía, no sea una aproximación respetable, sino sobre todo porque el juego de todo o nada a que conduce desvía la atención de lo que probablemente es lo decisivo, como es si hay o no razones de sentido común y justicia que se opongan a un régimen de imposición automática, sin consideración de ningún factor adicional, de sanciones administrativas a las personas jurídicas por hechos de sus empleados en el desempeño de sus funciones.

\section{LA PERSPECTIVA RACIONAL-INSTRUMENTAL}

Desde una perspectiva racional-instrumental la cuestión es si resulta sensato imponer sanciones a una persona jurídica cuando quienes controlan y son responsables por el funcionamiento de la organización subyacente no han estado en condiciones de evitar, a pesar de todos sus esfuerzos, que algún empleado incurra puntualmente en un hecho ilícito en el desempeño de sus funciones. Porque, aparte de consideraciones de justicia, hay también razones instrumentales asociadas a las funciones del Derecho, en particular de las ramas jurídicas que imponen sanciones, y a la manera mínimamente racional en que pueden cumplirlas.

Considérese esto último por ahora solo en relación con las personas naturales. Si se asume que el medio a través del cual la amenaza de una sanción para el evento de infracción normativa puede cumplir con sus cometidos sociales es motivando a los destinatarios de las prescripciones en cuestión para que las acaten, solo tiene sentido hablar de una infracción del Derecho o, al menos, solo tiene sentido que de la infracción se sigan consecuencias jurídicas con carácter de sanción ${ }^{12}$ si el destinatario de la norma ha estado en condiciones de motivarse por ella y, consecuentemente, de acatarla. Cuando tal no es el caso la sanción carece de sentido, tanto para el sujeto sometido a sanción como para el resto de los miembros de la comunidad, porque en la medida en que el sujeto simplemente no estuvo en condiciones de comportarse correctamente, la sanción no tiene nada que ver con algo que esté bajo su control, con algo que él pueda mejorar, sino que cae sin más sobre él como una calamidad, como destino ciego e inmodificable.

Y ciertamente no es esta una estrategia sensata de sanción, visto desde cualquiera de los enfoques a partir de los cuales se ha pretendido justificar el castigo: desde luego porque no hay nada que expiar ni nada que corregir en quien no se ha puesto en una posición contraria al Derecho y no hay nada que prevenir si la infracción y el castigo no dependen del cuidado o empeño que se ponga en satisfacer las exigencias del Derecho, porque se responde a todo evento. Más bien al contrario, un esquema de sanciones de este tipo lo único que

12 Otra cosa puede ser, por cierto, si se trata no ya de sanciones sino de la distribución del riesgo económico por ciertos daños. Al respecto véase la síntesis de BARros (2006) $\$ 36$ ( $\mathrm{N}^{\circ} 304$ ss., pp. 450 ss.). 
puede provocar es el desincentivo de los esfuerzos por estar a la altura de los dictados del Derecho, porque si no importa mayormente el esfuerzo y se debe responder en todo caso si algo sale mal, aun por causas totalmente independientes e incontrolables, bien puede salir más a cuenta no realizar dicho esfuerzo y limitarse a orar para que no pase nada malo ${ }^{13}$.

Si se lleva ahora la reflexión al ámbito de la responsabilidad de las personas jurídicas, las conclusiones desde un punto de vista de racionalidad instrumental son exactamente las mismas. Por cierto no se trata en este caso de la motivación de la propia persona jurídica, sino de la motivación de quienes están a cargo de ella para que desplieguen los mayores y mejores esfuerzos para que no se infrinja la ley en el seno de la organización. Desde esta perspectiva, tampoco es sensato imponer sanciones sin más a la persona jurídica por el solo hecho de la infracción cometida por un empleado en el desempeño de sus funciones, con independencia de los esfuerzos desplegados para impedirlo por parte de quienes están a su cargo. En la medida en que es imposible precaver en términos absolutos la realización de actos ilícitos en una organización, tanto más en una organización compleja, la irrelevancia de los esfuerzos puestos en asegurar el imperio del Derecho deja a esos responsables en la misma situación descrita, en la que solo cabe la oración.

Ahora bien, a diferencia de lo que puede ocurrir con las sanciones a las personas naturales, las sanciones a las personas jurídicas persiguen por definición propósitos exclusivamente instrumentales, y por regla general de carácter regulatorio. Si esto es así, es decir, si las sanciones a la persona jurídica son herramientas regulatorias, entonces lo que tiene sentido es conectar una posible sanción no al dato bruto de la contrariedad objetiva con el Derecho, sino solo a una infracción que además exprese un comportamiento disfuncional a los propósitos regulatorios. En concreto, la sanción debe servir como incentivo para cierto tipo de comportamiento, de modo que cuando ese objetivo está debidamente logrado no debiera imponerse sanción alguna ${ }^{14}$.

Esto se ve con mayor claridad aún, cuando se toma conciencia de que una de las razones principales por las cuales las sanciones no se reservan solo a los individuos que intervienen en la infracción, sino que se extienden también a las personas jurídicas en las que estos se desempeñan, a pesar de que a su respecto la idea misma de reproche tiene siempre algo de artificial, es precisamente obligar ("motivar coactivamente") a estas últimas, a través de los responsables de su organización, para que adopten mecanismos eficaces de control y prevención, en lo que se da en llamar una enforced self-regulation ${ }^{15}$. Aunque la prevención y detección de una posible actividad ilícita es, por cierto, en primera línea un cometido estatal, atendidas las dificultades que enfrentan los poderes públicos para conocer lo que ocurre intramuros de las organizaciones empresariales, se procura involucrar activamente a las propias empresas en la tarea ${ }^{16}$.

\footnotetext{
En esa línea Yeung (2004) p. 85.

Montt (2011) p. 286.

15 Desde la perspectiva penal véase la formulación original de Braithwaite (1982); también Nieto Martín (2008 a) pp. 215 ss.; Nieto Martín (2008 b) p. ss. Desde la perspectiva regulatoria Montt (2011) p. 282, con

16 Sobre esto, en perspectiva penal, Hernández (2010) pp. 218 ss., con referencias.
} referencias. 
Pues bien, en este contexto la imposición automática de sanciones a la persona jurídica con independencia de los esfuerzos de sus encargados solo puede resultar contraproducente. En efecto, si conceptualmente no hay ningún modo en que la persona jurídica pueda liberarse de responsabilidad cuando alguna persona natural perteneciente al círculo de sujetos relevantes incurre en una conducta ilícita bajo las circunstancias objetivas previstas por la ley, la pregunta es por qué habría de preocuparse la empresa por adoptar medidas costosas para impedirlo. Sin duda la evitación de las consecuencias más o menos graves asociadas a la responsabilidad (multas, responsabilidad civil, descrédito corporativo, incluso eventual disolución) puede constituir una razón poderosa para reducir per se los riesgos de infracción, pero esto solo dentro de ciertos límites acotados, porque si los mayores y mejores esfuerzos simplemente no serán recompensados, a partir de un punto ya no existe mayor incentivo para realizar tales esfuerzos mayores y mejores, y más conviene pensar en paliativos de los efectos de posibles condenas, con lo cual lo que se quiere incentivar simplemente ya no se incentiva ${ }^{17}$.

Más bien al contrario. Si la existencia de un buen programa de cumplimiento nunca puede liberar de responsabilidad a la persona jurídica en caso de infracción, se produce la paradoja de que las empresas más serias y preocupadas quedan más expuestas a sanción que aquellas que han hecho menos esfuerzo, porque un buen modelo de cumplimiento, a través de sus mecanismos de control, debiera, entre otras cosas, proveer de más y mejor información que puede servir de material probatorio en contra de la persona jurídica ${ }^{18}$. En semejante escenario, resulta obvio que la racionalidad instrumental lleva a no contar con un buen sistema de cumplimiento o, si se cuenta con él y a pesar de todo se comete una infracción, lleva a que en vez de esmerarse en aclarar el hecho y poner rápidamente todos los antecedentes a disposición de la autoridad, el sujeto trate de ocultarlos. Esto explica que, en ausencia de mecanismos de exoneración de responsabilidad para la persona jurídica ante infracciones cometidas por algunos de sus empleados, los intereses de ambas partes tiendan a alinearse naturalmente contra la acción de los órganos estatales de fiscalización y persecución ${ }^{19}$.

Estos son obviamente efectos perversos de una mala decisión normativa. Lo racional y justo es que la persona jurídica pueda eximirse de responsabilidad por hechos de sus subordinados si logra probar que el hecho se produjo a pesar de los esfuerzos exigibles desplegados por evitarlo. Solo en ese escenario vale la pena el esfuerzo y no representa un peligro contar con un buen sistema interno de control e información, al tiempo que se mantiene una sana tensión entre los intereses del infractor individual y los de la organización, todo esto en directo beneficio de los fines regulatorios de la autoridad.

\footnotetext{
Entre nosotros MonTt (2011) pp. 286 ss., con referencias.

Montt (2011) p. 287.

Montt (2011) p. 288.
} 


\section{La nítida tendencia del Derecho comparado}

Lo anterior no es mera especulación sobre modelos ideales de regulación, sino que responde inequívocamente a la tendencia que se aprecia en el Derecho comparado en materia de responsabilidad de las personas jurídicas. El desarrollo normativo más claro de estas ideas en el Derecho comparado se encuentra en la regulación de la responsabilidad penal de las personas jurídicas, fenómeno relativamente reciente en la tradición jurídica europeo-continental pero conocido desde antiguo en el mundo anglosajón.

Es así como la crítica fundamental que se le dirige al modelo de responsabilidad automática que existe en países como los Estados Unidos (responsabilidad vicarial) o el Reino Unido (doctrina de la identificación) en materia de responsabilidad penal de las personas jurídicas, gira precisamente en torno a lo disfuncional que resulta, por concepto de pérdida de incentivos o producción de incentivos perversos, que las personas jurídicas sean castigadas a todo evento, a despecho de los esfuerzos que se hacen en su seno para asegurar el imperio del Derecho ${ }^{20}$.

Es indudable que esto es lo que subyace a la práctica de determinación de penas para organizaciones en los Estados Unidos, donde tiene su origen más nítido la idea de la responsabilidad por "defecto de organización". En efecto, fueron las Directivas para la determinación de penas para organizaciones, las Sentencing Guidelines for Organizations de 1991 las que primero asociaron los esfuerzos preventivos de la actividad ilícita desplegados por la organización con las consecuencias que dicha actividad ilícita debía acarrear para ella, un modelo que luego se ha extendido internacionalmente.

El establecimiento de un modelo de cumplimiento efectivamente adecuado es una herramienta a través de la cual no solo se puede obtener una atenuación del rigor sancionatorio, dando lugar a sanciones muy bajas o solo nominales, cuya ejecución queda suspendida a prueba, sino que incluso sirve para obtener una liberación del posible castigo, en cuanto presupuesto suficiente para una solución procesal negociada (los llamados DPA [Deferred Prosecution Agreements] y NPA [Non-Prosecution Agreements]), que implica la no persecución de la responsabilidad de la persona jurídica. Por cierto se trata de una práctica relativa solo a la decisión discrecional de persecución o a la determinación de la sanción concreta a imponer, esto es, solo relevante para el quantum de la sanción, pero no para la cuestión previa sobre la procedencia de dicha sanción, de modo que con esto no está en cuestión la vigencia del modelo vicarial tradicional y característico del Derecho de los Estados Unidos, pero no puede negarse que en los hechos los efectos del establecimiento de un modelo de cumplimiento efectivamente adecuado van mucho más allá que la simple atenuación del castigo.

Precisamente porque el régimen legal en el Derecho estadounidense aún no se ha visto modificado en lo formal, es tanto más importante la consagración expresa de exigencias de "defecto de organización" o de "defensas de cumplimiento" en otro ordenamiento jurídico con larga tradición de sanción a las personas jurídicas sobre base exclusivamente objetiva, como es el caso del Reino Unido. Ya en 2007, con la introducción de la ley sobre

20 Entre muchos otros Weissmann y Newman (2007) pp. 411 ss.; Pollack (2009) pp. 1393 ss.; Bucy (2009) pp. 1437 ss.; Gobert y Punch (2003) pp. 78 ss. 
homicidio corporativo (Corporate Manslaughter and Corporate Homicide Act), mediante la cual se quiso ampliar el círculo de personas naturales cuya conducta podía gatillar la responsabilidad de la persona jurídica, de modo que también el hecho de simples empleados sin poderes de dirección pudiera hacerlo ${ }^{21}$, el legislador británico estableció como requisito de la responsabilidad penal de una organización por la muertes ocurridas con ocasión de su funcionamiento la circunstancia de haber organizado o gestionado sus actividades de un modo gravemente defectuoso. En efecto, la Sección 1 (1) de la Ley dispone que una organización de aquellas a las que ella resulta aplicable es responsable del delito "si la forma en que sus actividades se gestionan u organizan (a) causa la muerte de una persona, y (b) equivale a una infracción grosera de un deber relevante de cuidado debido por la organización al difunto" 22 .

Y más recientemente, en el mismo país se ha previsto una "defensa de cumplimiento" en la célebre Bribery Act de 2010, vigente desde julio de 2011. Como su nombre indica, se trata de una ley de objeto acotado, exclusivamente referida al cohecho (también entre privados), pero que es indicativa de la inequívoca tendencia en orden a tener en cuenta, a la hora de la posible imposición de una sanción, la organización que se ha dado la empresa. Pues bien, en lo que concierne a las personas jurídicas (relevant commercial organisations) se establece un tipo penal corporativo consistente en el fracaso en prevenir y evitar actos de corrupción en su seno (Failure of commercial organisations to prevent bribery), contexto en el cual, sin embargo, se prevé expresamente la defensa consistente en probar que se han implementado procedimientos adecuados tendientes a impedir que personas vinculadas emprendan tal conducta (Sec. 7 [2] $)^{23}$. La recepción de esta innovación en el mundo académico y de la práctica ha sido muy favorable y se ha sostenido la conveniencia de que el símil de esta legislación en los Estados Unidos, la FCPA (Foreign Corrupt Practices Act), acoja también una solución equivalente ${ }^{24}$.

Si esto es así en ordenamientos que siguen en general aferrados a una larga tradición de responsabilidad automática de las personas jurídicas y que ni siquiera excluyen completamente la posibilidad de responsabilidad penal objetiva incluso respecto de personas naturales $^{25}$, se explica entonces que en ordenamientos más sensibles a la idea de culpabilidad, llegado el momento de introducir una responsabilidad penal de las personas jurídicas, se haya adoptado la idea de las Guidelines estadounidenses, pero dando el paso siguiente obvio (ya dado en particular por las mencionadas leyes británicas) de entender que el esfuerzo

\footnotetext{
21 Sin perjuicio que sigue vigente una referencia a la "plana mayor" en la medida en que se exige que la forma en que las actividades han sido organizadas o gestionadas por la dirección superior (senior management) debe ser un elemento sustancial de la infracción de deberes de cuidado (Sec. 1 [3]).

22 En general sobre esta ley, GRIFFIn (2006) pp. 151 ss.

23 "But it is a defence for $C$ [la organización] to prove that $C$ had in place adequate procedures designed to prevent persons associated with $C$ from undertaking such conduct".

24 Jordan (2011) pp. 25 ss.

25 Como se sabe, hay contextos en que está permitida la strict liability en materia penal respecto de personas naturales. Sobre esto, para los Estados Unidos Strader (2011) pp. 28 ss.; para el Reino Unido Ormerod (2005) pp. 137 ss.; o SiMESTER et al. (2013) pp. 173 ss.
} 
efectivamente serio por impedir la actividad ilícita no solo debe servir para aminorar la responsabilidad de la persona jurídica, sino derechamente también para eximirla de ella ${ }^{26}$.

Es lo que se aprecia con toda claridad en la evolución del Derecho penal (nacional) europeo de las personas jurídicas. Si se observan los requisitos de la responsabilidad de las personas jurídicas en países como Suiza ${ }^{27}$, Austria ${ }^{28}$ Italia $^{29}$ o España ${ }^{30}$ se observa cómo es

26 En la discusión continental la idea de "defecto de organización" (o "culpabilidad organizacional") fue introducida por Tiedemann (1988) pp. 1172 ss., si bien inicialmente como fundamento abstracto y no como eximente.

27 El Art. 102 del Código penal suizo conoce dos hipótesis: respecto de cualquier crimen o simple delito cometido en la empresa y en el marco de fines de la empresa, la persona jurídica responde cuando "por la defectuosa organización de la empresa" no es posible imputarle el hecho a ninguna persona natural; y respecto de un listado reducido de delitos típicamente "empresariales" y sensibles, con independencia de la posible responsabilidad de una persona natural, cuando se le puede reprochar a la persona jurídica "que no ha adoptado todas las medidas organizativas necesarias y exigibles para impedir tal delito". Véase StratenWerth y Wohlers (2013) Art. 102, marg. 3 ss.

28 En Austria, el $\$ 3$ de la Ley de Responsabilidad de las Asociaciones (Verbandsverantwortlichkeitsgesetz VbVG) de 2005, respecto de cualquier delito cometido en beneficio de la persona jurídica o con infracción de deberes propios de ella, distingue según si lo ha cometido un sujeto con poder de decisión o bien otro tipo de empleado: en el primer caso la persona jurídica responde siempre (supuesto que el individuo haya actuado antijurídica y culpablemente), en tanto que en el segundo (dadas las exigencias subjetivas del tipo en cuestión) solo cuando "la comisión del delito fue posibilitada o esencialmente facilitada por el hecho de que sujetos con poder de decisión han desatendido el cuidado debido y exigible según las circunstancias, especialmente porque han omitido las medidas técnicas, organizativas o de personal esenciales para impedir tales hechos". Véase STEININGER (2006) $\$ 3$ marg. 34 ss.

29 En Italia, el Art. 5 del Decreto Legislativo $\mathrm{N}^{\circ}$ 231, de 2001, sobre responsabilidad de las personas jurídicas emanada de delito, dispone que la persona jurídica responde por delitos cometidos en su interés o beneficio tanto por sujetos con rango directivo como por sujetos bajo la dirección o vigilancia de alguno de los anteriores, para luego establecer, en los Arts. 6 y 7, requisitos adicionales diferenciados según el tipo de sujeto: tratándose de directivos, la persona jurídica responde por regla general, a menos que pruebe que "a) el órgano dirigente ha adoptado e implementado eficazmente, antes de la comisión del hecho, modelos de organización y gestión idóneos para prevenir delitos de la especie de aquel que se ha verificado; b) el deber de vigilar el funcionamiento y la observancia de los modelos y su actualización ha sido confiada a un órgano del ente dotado de poderes autónomos de iniciativa y de control; c) las personas han cometido el delito eludiendo fraudulentamente los modelos de organización y de gestión; d) no ha habido omisión de (o insuficiente) vigilancia por parte del órgano a que se refiere la letra b)" (Art. 6.1); tratándose de no directivos, la persona jurídica responde cuando el delito ha sido posible por la inobservancia de los deberes de dirección y vigilancia (Art. 7.1), inobservancia que se excluye cuando "antes de la comisión del delito, el ente ha adoptado e implementado eficazmente un modelo de organización, gestión y control idóneo para prevenir delitos de la especie de aquél que se ha verificado" (Art. 7.2). Véase BernasConi (2008) pp. 97 ss.

30 El art. 31 bis del Código penal español en su nueva versión de 2015 contiene una regulación prácticamente idéntica a la italiana, y distingue en su apartado 1 entre delitos cometidos por los "representantes legales o por aquellos que actuando individualmente o como integrantes de un órgano de la persona jurídica, están autorizados para tomar decisiones en nombre de la persona jurídica u ostentan facultades de organización y control dentro de la misma" (letra a) y los cometidos por quienes están "sometidos a la autoridad" de los anteriores (letra b). En el primer caso la persona jurídica solo se exime de responsabilidad "si se cumplen las siguientes condiciones: $1^{\circ}$ el órgano de administración ha adoptado y ejecutado con eficacia, antes de la comisión del delito, modelos de organización y gestión que incluyen las medidas de vigilancia y control idóneas para prevenir delitos de la misma naturaleza o para reducir de forma significativa el riesgo de su comisión; $2^{\circ}$ la supervisión del funcionamiento y del cumplimiento del modelo de prevención implantado ha sido confiada a un órgano de la persona jurídica con poderes autónomos de iniciativa y de control o que tenga encomendada legalmente la función de supervisar la eficacia de los controles internos de la persona jurídica; $3^{\circ}$ los autores individuales han 
una constante que la simple infracción de un empleado en el desempeño de sus funciones, aunque ello reporte algún tipo de beneficio potencial para la persona jurídica, no basta por regla general para gatillar la responsabilidad de esta, sino que se impone la exigencia adicional de un "defecto de organización" del ente colectivo al que sea posible conectar el hecho individual.

Y como es sabido, es también este el modelo que se ha adoptado en Chile a la hora de introducirse entre nosotros la responsabilidad penal de las personas jurídicas mediante la Ley $\mathrm{N}^{\circ} 20.393$ del año 2009. En efecto, la atribución de responsabilidad penal de la persona jurídica por los delitos relevantes ${ }^{31}$ cometidos por personas naturales pertenecientes a un cierto círculo de sujetos relevantes adscritos a ella, supone que el sujeto en cuestión haya cometido el respectivo delito al menos en parte en interés o para beneficio de la persona jurídica y que dicho delito haya sido consecuencia del incumplimiento por parte de la persona jurídica de sus deberes de dirección y supervisión, lo que en concreto se da cuando la persona jurídica carece de un modelo adecuado de prevención de delitos ${ }^{32}$. En otras palabras, también en Chile se ha entendido que la manera racional de conectar los hechos de sujetos individuales que actúan en el contexto de la actividad empresarial con la responsabilidad de la persona jurídica que sirve de expresión jurídica de la empresa es a través de la exigencia de un "defecto de organización" o, dicho en otros términos, de un déficit en el esfuerzo de cumplimiento.

Ahora bien, es manifiesto que esta lógica no tiene sentido solo para el Derecho penal, sino que para cualquier rama del Derecho que imponga sanciones, en particular en el ámbito del Derecho administrativo sancionador.

Un buen ejemplo de aplicación de estas ideas, configurado antes incluso del actual auge de la idea de compliance como presupuesto y medida de la responsabilidad de las personas jurídicas, se encuentra en la Ley de infracciones administrativas alemana, la OWiG (Ordnungswidrigkeitengesetz) de 1968.

A primera vista esta afirmación podría sorprender, porque el $₫ 30 \mathrm{OWiG}$, la disposición que regula la imposición de multas administrativas a la persona jurídica en virtud de delitos o infracciones administrativas cometidos por sujetos relacionados con ella, con infracción de deberes propios de la persona jurídica o que la han enriquecido (o han debido hacerlo), no contiene ninguna exigencia adicional de incumplimiento de deberes o de

cometido el delito eludiendo fraudulentamente los modelos de organización y de prevención y $4^{\circ}$ no se ha producido una omisión o un ejercicio insuficiente de sus funciones de supervisión, vigilancia y control por parte del órgano al que se refiere la condición $2^{\circ ”}$ (apartado 2). En el segundo caso se requiere que los sujetos hayan podido realizar los hechos "por haberse incumplido gravemente por aquéllos [los directivos] los deberes de supervisión, vigilancia y control de su actividad atendidas las concretas circunstancias del caso" (apartado 1, letra b), lo que conecta con el apartado 4, que prevé la exención de responsabilidad de la persona jurídica respecto de los hechos de estos sujetos "si, antes de la comisión del delito, ha adoptado y ejecutado eficazmente un modelo de organización y gestión que resulte adecuado para prevenir delitos de la naturaleza del que fue cometido o para reducir de forma significativa el riesgo de su comisión”. Sobre la nueva regulación véase SiLva SÁNCHEZ (2016) pp. 869 ss.

31 Lavado de dinero, financiamiento del terrorismo, soborno y, desde la Ley $\mathrm{N}^{\circ} 20.931$, de 5 de julio de 2016, receptación.

32 Art. $3^{\circ}$ LeY N 20.393 de 2009. 
organización defectuosa, como tampoco prevé alguna posible exención de responsabilidad por esfuerzo de cumplimiento. Debe considerarse, sin embargo, que los sujetos relevantes para los efectos del $\$ 30 \mathrm{OWiG}$ son exclusivamente sujetos con responsabilidades directivas (representantes y miembros de órganos superiores de diversos tipos de personas jurídicas $y$, en general, sujetos que responden por la dirección de la empresa, incluyendo a quienes ejercen funciones superiores de vigilancia y control), los que, sin embargo, suelen no estar directamente implicados en los hechos ilícitos. Es por esta razón que en la mayor parte de los casos las multas que se imponen en virtud del $\$ 30$ OWiG lo son "a través" de otra disposición de la Ley, el $\$ 130 \mathrm{OWiG}$, que tipifica como infracción administrativa la inobservancia de los deberes de vigilancia en la empresa, concretamente de la vigilancia destinada a prevenir la comisión de delitos o infracciones administrativas por parte de empleados subalternos, que son los casos más comunes en la práctica ${ }^{33}$.

Así, en la medida en que alguno de los sujetos relevantes para los efectos del $\$ 30$ OWiG incurre en la conducta prevista en el $\$ 130$ OWiG, esto es si "dolosa o imprudentemente omite las medidas de vigilancia que son necesarias para impedir en la empresa incumplimientos de deberes que conciernen al dueño y cuya infracción está conminada con pena o multa administrativa”, y adicionalmente se da la condición objetiva para la sanción, consistente en que efectivamente "se comete un incumplimiento de ese tipo que con la debida vigilancia se hubiera impedido o dificultado esencialmente", dichos sujetos responden por su propia infracción ${ }^{34}$, pero al mismo tiempo gatillan la responsabilidad de la persona jurídica por aplicación del $\$ 30 \mathrm{OWiG}$.

Y como se desprende de la sola lectura del tipo administrativo del $\$ 130$ OWiG, este exige que en la empresa no se hayan adoptado las medidas de vigilancia necesarias para impedir o dificultar esencialmente la ocurrencia de hechos ilícitos, agregándose de modo expreso que entre tales medidas se considera también la "contratación, selección cuidadosa y control de personal a cargo de la vigilancia". De modo que si la empresa cuenta con un sistema adecuado de vigilancia destinado a la prevención de hechos ilícitos en el funcionamiento de la actividad empresarial, no puede haber responsabilidad de los sujetos en posición directiva ni tampoco de la persona jurídica. La aplicación del $₫ 130$ OWiG ha dado lugar a muy considerable literatura y jurisprudencia, a través de la cual se ha ido precisando el contenido de los deberes de vigilancia, su necesidad y exigibilidad, tanto en general como en contextos específicos ${ }^{35}$, en unos términos ampliamente coincidentes con los que exhiben los "programas de cumplimiento" en otras tradiciones jurídicas ${ }^{36}$, sin contar con

\footnotetext{
33 Sobre esto existe amplio acuerdo: el $\$ 130 \mathrm{OWiG}$ es la fuente principal de multas a las personas jurídicas en virtud del $₫ 30$ OWiG; véase, por todos, Rogall (2014) $\$ 30$ marg. 92 y $\$ 130$ marg. 6.

34 En rigor, el tipo administrativo del $\$ 130 \mathrm{OWiG}$ es un tipo "especial", en el sentido que no lo puede realizar cualquiera, sino solo el dueño (Inhaber) de la empresa, de modo que la responsabilidad de esos sujetos, que no poseen la calidad de dueño, se deriva de la regla de actuar en lugar de otro del $\$ 9 \mathrm{OWiG}$, conforme a la cual también responden por los tipos especiales los representantes y quienes han recibido poderes de dirección (un círculo de sujetos no idéntico pero muy similar al del $₫ 30 \mathrm{OWiG}$ ) de quien sí tiene la calidad exigida por el respectivo tipo administrativo.

35 Sobre esto, por todos, Rogall (2014) $\$ 130$ marg. 38 ss.

36 Así también Rogall (2014) \$130 marg. 57 s.
} 
que la práctica alemana ha adoptado sin ambages el término corporate compliance para referirse al conjunto de medidas destinadas a evitar responsabilidad de las empresas por hechos ilícitos cometidos en su seno ${ }^{37}$.

Un aspecto de la situación alemana que puede ser relevante para la discusión en Chile es que en Alemania está fuera de duda la vigencia del principio de culpabilidad en materia de infracciones y sanciones administrativas, pues se entiende que estas son expresión del ius puniendi estatal, al punto que la OWiG consagra como regla general la exigencia de dolo y establece un sistema de numerus clausus en cuanto a la suficiencia de culpa ${ }^{38}$, tal como ocurre en materia penal, tanto en Alemania como en Chile. Pero nada se dice respecto de las personas jurídicas (al margen de exigirse lo que rija para la persona natural que actúa en el caso concreto), contexto para el cual estaban abiertas distintas soluciones, habiéndose llegado en la práctica a un modelo en que solo los hechos de los directivos dan lugar a responsabilidad automática del ente, en tanto que los hechos de subordinados solo producen tal responsabilidad cuando obedecen a defectos de la organización.

Ahora bien, como podría objetarse que en Alemania esto es así por una decisión explícita del legislador (pues en los hechos es decisivo el tenor del $\$ 130 \mathrm{OWiG}$ ), conviene aproximarse a un ordenamiento que carece de regulación expresa de la responsabilidad administrativa de las personas jurídicas, como es el caso español. En España, la vigencia del principio de culpabilidad en materia de infracciones y sanciones administrativas se expresa actualmente en el art. 28.1 de la Ley 40/2015, de 1 de octubre, de Régimen Jurídico del Sector Público, según el cual cualquier sanción supone dolo o culpa ${ }^{39}$. En lo que concierne a la responsabilidad de las personas jurídicas, a pesar de que estas están expresamente mencionadas en el precepto, no se agrega nada más, de modo que, en la medida en que a su respecto no es conceptualmente posible apreciar dolo ni culpa, se han abierto diversas variantes interpretativas. Lo que interesa destacar es que la posibilidad de una responsabilidad automática ha sido desechada por la jurisprudencia del Tribunal Constitucional español, tribunal que, luego de afirmar la vigencia del principio de culpabilidad, ha sostenido que este no se opone a la responsabilidad administrativa directa de las personas jurídicas, respecto de las cuales la exigencia de culpa de ningún modo desaparece, sino solo que el

\footnotetext{
37 Véase, por ejemplo, textos como el de Hauschka (2010).

$38 § 10$ OWiG de 1968.

39 El art. 28.1 es del siguiente tenor: "Solo podrán ser sancionadas por hechos constitutivos de infracción administrativa las personas físicas y jurídicas, así como, cuando una Ley les reconozca capacidad de obrar, los grupos de afectados, las uniones y entidades sin personalidad jurídica y los patrimonios independientes o autónomos, que resulten responsables de los mismos a título de dolo o culpa". Hasta 2016 regía el art. 130.1 de la Ley 30/1992, de 26 de noviembre, de Régimen Jurídico de las Administraciones Públicas y del Procedimiento Administrativo Común ("Solo podrán ser sancionadas por hechos constitutivos de infracción administrativa las personas físicas y jurídicas que resulten responsables de los mismos aun a título de simple inobservancia”), cuya referencia a la "simple inobservancia" había provocado cierta discusión, no obstante lo cual se sostenía mayoritariamente que lo mínimo que exigía la responsabilidad administrativa era culpa por parte del agente. Al respecto, por la tesis minoritaria pero con referencias a la mayoritaria, Nieto (2012) pp. 342 ss., en particular p. 346 ss.; Huergo Lora (2007) pp. 386 ss. La importancia de este escenario legal, que acaba de ser superado, radica en que, no obstante él, se impuso en España una interpretación contraria a la responsabilidad automática de la persona jurídica.
} 
principio "se ha de aplicar necesariamente de forma distinta a como se hace respecto de las personas físicas" ${ }^{\prime \prime}$.

Al margen de lo más o menos convincente que puede ser la afirmación precedente ${ }^{41}$, lo relevante para los fines de este trabajo es que a ella subyace la idea, que aquí se comparte, de que la responsabilidad de la persona jurídica, al margen de la discusión sobre si es o no "objetiva”, no tiene por qué ser automática, y más aún, que resulta irracional e injusto que pueda ser automática, ante lo cual procede buscar caminos que permitan aplicar alguna idea de "culpabilidad" distinta pero de algún modo emparentada con la que rige respecto de las personas naturales. De este modo, aunque sobre el particular dista de haber consenso en España, una importante corriente de opinión mantiene que debe exigirse precisamente incumplimiento de deberes de vigilancia y control y, en cierto modo, "defecto de organización” en los términos que vienen desarrollándose aquít ${ }^{42}$.

Como se puede ver, el panorama del Derecho comparado, si bien centrado en ordenamientos jurídicos del mundo desarrollado que tradicionalmente han ejercido influencia en nuestro medio, muestra una nítida tendencia hacia la superación de una responsabilidad automática de las personas jurídicas.

\section{Signos incipientes en la práctica SANCIONATORIA CHILENa: El EJEMPlo de las SANCIONES EN MATERIA DE LIBRE COMPETENCIA}

La interpretación esbozada es consistente con ciertos signos incipientes de la práctica sancionatoria en áreas específicas del ordenamiento jurídico chileno. Un buen ejemplo de esto lo provee la práctica en materia de libre competencia ${ }^{43}$. Si bien hasta la fecha las autoridades competentes no han afirmado nunca que la existencia de programas de cumplimiento adecuados y efectivamente implementados pueda eximir de responsabilidad por hechos cometidos por empleados subalternos, es al mismo tiempo evidente la importancia capital que tanto la Fiscalía Nacional Económica (FNE) como el Tribunal de Defensa de la Libre Competencia (TDLC) le asignan a la existencia de tales programas, al punto no solo de valorarlos, sino que de promoverlos sin reservas e incluso de imponerlos de un modo más o menos coercitivo.

En efecto, en el contexto de acuerdos extrajudiciales entre la FNE y las personas jurídicas imputadas, el TDLC ha validado acuerdos en los que la empresa se obliga precisa-

40 STC 246/1991, de 19 de diciembre de 1991, FJ Nº 2.

41 Crítico Nieto (2012) p. 398, quien, sin embargo, más allá de acusar inconsistencia, no puede negar los efectos prácticos del pronunciamiento.

42 La construcción original en torno a una culpa in vigilando de la persona jurídica proviene al parecer de Rebollo Puig (1989) pp. 766 ss. Véase también, con referencias a jurisprudencia ordinaria, Lozano (1992) pp. 227 ss.; y más modernamente Gómez Tomillo y SAnz Rubiales (2010) pp. 529 ss.

43 Es este el contexto en el que la conexión entre modelos de cumplimiento y determinación de sanciones se aprecia con mayor claridad, pero ciertamente no pueden descartarse desarrollos similares en la práctica sancionatoria de autoridades competentes en otras áreas, que también promueven mecanismos internos de prevención similares, tales como la Superintendencia de Valores y Seguros (y su Norma de Carácter General N 309, de 2011, sobre principios de gobierno corporativo y sistemas de gestión de riesgo y control interno, modificada mediante la NCG $\mathrm{N}^{\circ} 408$, de 31 de marzo de 2016), entre otras. 
mente a establecer programas de cumplimiento ${ }^{44}$, en tanto que en sentencias condenatorias ha considerado expresamente la ausencia de un adecuado programa de cumplimiento para reprocharle a una persona jurídica no haber actuado "con toda la diligencia debida" ${ }^{45}$, reproche que no tendría ningún sentido si en efecto rigiera en la materia una responsabilidad (objetiva) automática de las personas jurídicas. Por último, también en sentencias condenatorias, ha impuesto derechamente la obligación de darse un programa de cumplimiento ${ }^{46}$.

La pregunta que surge inmediatamente es: si una empresa cumple con el óptimo definido por el propio tribunal competente en la materia, al punto de imponerlo como sanción a otras empresas en que se producen infracciones similares ¿cuál sería entonces la razón por la cual habría de sancionarse a dicha empresa? No parece haber justificación para que se le imponga la sanción de organizarse como ya lo ha hecho o que se le condene al pago de una multa a pesar de estar bien organizada, solo porque tuvo la mala suerte de que, no obstante ello, un empleado subalterno infringió la ley.

Por su parte, la FNE ha elaborado y promovido el uso de una Guía sobre "Programas de Cumplimiento de la Normativa de Libre Competencia" (Material de promoción $\mathrm{N}^{\circ} 3$, junio de 2012), en la que la FNE destaca, entre los beneficios del establecimiento de un programa de cumplimiento, la posibilidad de una rebaja de la multa aplicable: "En aquellos casos en que a pesar de existir un buen Programa de Cumplimiento algún traba-

44 Así, por ejemplo, la conciliación acordada entre la FNE y FASA, en FNE CONTRA CAdENAS DE FarmaCias (2009): "FASA se obliga a elaborar, en un plazo de 60 días hábiles contados desde que la presente resolución quede ejecutoriada, un código interno para desincentivar toda conducta contraria a la libre competencia y a prohibir a sus ejecutivos mantener propiedad o participación alguna -directa o indirecta- en las otras requeridas, así como en la administración de sus negocios" (c. $3^{\circ}$ ).

45 FNe contra Compañía Chilena de Tabacos S.A. (2011), c. $155^{\circ}$.

46 Así, en FNE contra la Asociación Gremial de Ginecólogos Obstetras de la Provincia de Nuble y OTROS (2015) se ordena específicamente a la persona jurídica (asociación gremial) "implementar un programa de cumplimiento en materia de libre competencia que satisfaga los requisitos establecidos en la 'Guía de Programas de Cumplimiento de la Normativa de Libre Competencia' (material de promoción No 3) elaborada por la Fiscalía Nacional Económica, de junio de 2012. En especial, el programa deberá ajustarse a las necesidades y características propias de dicha asociación; contar con la participación activa de sus máximos dirigentes, quienes deberán nombrar un encargado interno del programa; y cumplir con las características de seriedad y completitud que permitan que el programa sea efectivo". Y confirmando lo que puede calificarse de tendencia, en FNE contra Asfaltos Chilenos S.A. y otros (2015), se impone a las requeridas "la adopción de un programa de cumplimiento en materia de libre competencia que satisfaga los requisitos establecidos en la 'Guía de Programas de Cumplimiento de la Normativa de Libre Competencia' (material de promoción No 3) elaborada por la Fiscalía Nacional Económica, de junio de 2012, por un plazo de cinco años”. Hay dos ministros (Sr. Menchaca y Sra. Domper) que se oponen a la imposición de esta obligación, pero no porque desconozcan la importancia capital de los programas de cumplimiento, sino solo porque entienden que su efectividad pasa porque se asuman voluntariamente y no vengan impuestos desde afuera. Otros dos ministros (Sr. Saavedra y Sr. Tapia) explicitan los elementos que, como mínimo, debería considerar el modelo de cumplimiento a implementar. Antes ya se había considerado la imposición de una obligación de este tipo en una prevención (de los ministros Sra. Butelmann y Sr. Depolo) a FNE contra Agrícola Agrosuper S.A. y otros (2014): "consideran apropiado imponer a cada una de las Empresas Avícolas Requeridas la obligación de establecer, implementar y ejecutar de forma permanente, a su costa y por a lo menos cinco años contados desde la fecha en que la sentencia quede ejecutoriada, un plan de cumplimiento y buenas prácticas competitivas administrado por terceros independientes y ajenos al control y a la gestión de cada una de ellas, del que deba darse cuenta formal y detalladamente a la Fiscalía Nacional Económica con una periodicidad a lo menos trimestral" (prevención 2 de los mencionados ministros). 
jador del agente económico cometa una infracción a la libre competencia, los mecanismos implementados podrán identificar aquellas faltas, permitiendo a la empresa adoptar las medidas pertinentes para ajustarse y hacer respetar la normativa sobre libre competencia, controlando así los daños causados por la comisión de la infracción. // La FNE considera que, incluso existiendo una infracción, la implementación de un correcto Programa de Cumplimiento otorga tres grandes beneficios: (i) posible rebaja de la multa a ser aplicada, en un contexto de un requerimiento ante el Tribunal de Defensa de la Libre Competencia; (ii) el uso oportuno del beneficio de la Delación Compensada, en caso que se trate de una colusión o cartel; y, (iii) posibilidad de llegar a un acuerdo extrajudicial” ${ }^{37}$.

Aunque la FNE pretenda que su guía es solo "material de promoción, y por consiguiente no tiene fuerza normativa”, es evidente que condensa su opinión, coincidente con la del TDLC, sobre el rol clave que un programa de cumplimiento adecuado está llamado a jugar en la apreciación de la responsabilidad que le puede caber a la persona jurídica a través de la cual se expresa una organización empresarial. Lo único objetable es que la FNE no extraiga la consecuencia obvia, como es que los programas de cumplimiento, en la medida en que son serios y adecuados, deben permitir no solo una atenuación de la sanción, sino la exención de la responsabilidad de las personas jurídicas que los han adoptado.

Una concepción automática de la responsabilidad de la persona jurídica no puede sino ser contraproducente en ámbitos en los que al mismo tiempo se apuesta por un fuerte desarrollo de programas de cumplimiento como la herramienta más efectiva para el logro de los fines regulatorios. Pues es evidente que este modelo solo puede desplegar todo su potencial si, junto con la amenaza del castigo y sus consecuencias, se consideran también suficientes incentivos positivos para la prevención de las infracciones que se busca evitar, en concreto, si los máximos esfuerzos exigibles se ven recompensados con la liberación de responsabilidad en casos en que la infracción era simplemente inevitable a pesar de dichos esfuerzos máximos exigibles.

\section{HECHOS DE LA "PLANA MAYOR" COMO POSIBLE LÍMITE DEL EFECTO EXIMENTE DE UN MODELO ADECUADO DE CUMPLIMIENTO}

Si bien lo que se ha dicho hasta ahora reclama validez general, no puede desconocerse que entre los sistemas que abrazan un modelo de responsabilidad por defecto de organización existen diferencias importantes a la hora de autorizar la exención de responsabilidad de la persona jurídica. Probablemente el punto en que estas diferencias se notan con mayor nitidez es el relativo al tratamiento que merecen los casos en que la infracción la ha cometido un directivo superior de la empresa, es decir, un miembro de lo que podría llamarse la "plana mayor" de la organización, contexto en el cual existe una clara tendencia o bien a la negación del efecto eximente del modelo de cumplimiento, o bien al menos a su fuerte restricción.

Tal reluctancia no causa extrańeza si se tiene en cuenta que en buena medida el origen de los modelos de responsabilidad automática de la persona jurídica, la teoría de la

47 Guía "Programas de Cumplimiento de la Normativa de Libre Competencia”, p. 17. 
identificación o del alter ego de la tradición inglesa, se construye precisamente (y en exclusiva) a partir de los hechos de los directivos superiores ${ }^{48}$, cuyas conductas, precisamente por su posición prominente en la empresa, podían considerarse, mediante una ficción, "hechos propios" de la persona jurídica (el directivo superior como el alter ego de la persona jurídica), ante lo cual, por cierto, no habría razones para exigir algo más a la hora de afirmar la responsabilidad de esta última. Desde esa perspectiva, las exigencias adicionales solo empiezan a percibirse como necesarias cuando el círculo de sujetos cuyas conductas pueden acarrear responsabilidad para la persona jurídica se va ampliando hasta alcanzar prácticamente a todos los empleados de la empresa.

Pero el punto de partida sigue haciendo sentido y la exoneración de responsabilidad es más difícil, cuando no imposible, en los casos en que la conducta en cuestión la ha desplegado un alto directivo. Si bien en el caso chileno la Ley $N^{\circ} 20.393$ no hace distingos y, por tanto, el defecto de organización es un requisito de responsabilidad también cuando se trata del comportamiento ilícito de los más altos responsables ${ }^{49}$, no han faltado voces escépticas respecto de que pueda exonerarse de responsabilidad una sociedad por un hecho cometido ni más ni menos que por su directorio o gerente general ${ }^{50}$, pues en tal caso parece difícil, en virtud de la misma ficción, decir que no ha sido la persona jurídica como tal la que ha actuado indebidamente, o que cuenta con un modelo adecuado de cumplimiento.

En otros ordenamientos el asunto viene derechamente zanjado por la ley. Así, por ejemplo, en materia penal, en las Guidelines estadounidenses se establece expresamente que la intervención activa o pasiva de "personal de alto nivel" en el hecho constituye un factor de agravación de la sanción (véanse los distintos supuestos del \$8C.2.5). Esto es lo que explica también la clara distinción que se hace en el Derecho italiano entre hechos cometidos por sujetos en "posición apical" y el resto de los empleados de la empresa. Mientras respecto de hechos de estos últimos la existencia, adecuación y suficiencia de un modelo de cumplimiento despliega todos sus efectos liberadores (art. $7^{\circ}$ ), respecto de hechos de los primeros se invierte la carga de la prueba y se aplica un estándar que apenas puede alcanzarse en la práctica $\left(\operatorname{art} .6^{\circ}\right)^{51}$. Y más clara aún fue la formulación original del Derecho español (2010), que solo preveía un efecto eximente de las medidas de dirección y supervisión exigibles respecto de los hechos de empleados subordinados, guardando silencio al respecto en relación con los órganos directivos ${ }^{52}$, lo que a todas luces, a despecho de la opinión contra-

\footnotetext{
$48 \mathrm{Al}$ respecto Gobert y Punch (2003) pp. 59 ss.

49 Más aún, una lectura a la rápida de la ley sugeriría que solo los hechos de la "plana mayor" acarrearían responsabilidad para la persona jurídica, pues en el inciso primero describe precisamente a ese círculo, para luego, en el inciso segundo, referirse a otros sujetos pero solo en la medida en que se encuentren bajo de dirección y supervisión directa de algún miembro del primer grupo. Sobre cómo queda sin efecto esa primera lectura restrictiva, HERNÁNDEZ (2010) p. 220.

50 Es lo que sugiere Matus (2013) p. 1.

51 Una visión jurisprudencial en Corso (2014) Art. $6^{\circ}$ pp. 74 ss., Art. $7^{\circ}$ pp. 95 ss.

52 El art. 31.1 CP en su versión de 2010 era del siguiente tenor: “1. En los supuestos previstos en este Código, las personas jurídicas serán penalmente responsables de los delitos cometidos en nombre o por cuenta de las mismas, y en su provecho, por sus representantes legales y administradores de hecho o de derecho. // En los mismos supuestos, las personas jurídicas serán también penalmente responsables de los delitos cometidos, en el ejercicio de actividades sociales y por cuenta y en provecho de las mismas, por quienes, estando sometidos a la
} 
ria de buena parte de la literatura especializada, expresaba la consagración de un modelo vicarial de responsabilidad respecto de la "plana mayor" 53 .

En lo que respecta ahora al Derecho administrativo sancionador, lo mismo cabe decir del Derecho alemán, según ya se expuso. Y en la muy escasa literatura chilena existente sobre la consideración de una "defensa de compliance" en este ámbito, específicamente en materia de libre competencia, se ha planteado también que la exoneración debe regir solo tratándose de hechos de empleados de rango medio y bajo, pero no de los ejecutivos de la empresa $^{54-55}$.

No es posible ni pertinente desarrollar aquí una toma de posición fundada sobre este punto, sobre todo porque se trata de una cuestión esencialmente debatible, que el legislador puede resolver de manera diversa, como muestra el Derecho comparado, de modo que mal se pueden hacer afirmaciones enfáticas en ausencia de texto legal expreso. Lo único que parece estar fuera de discusión es que en estos casos la exención, si cabe, debe ser excepcional y sometida a exigencias considerables. Más allá de esto, parece excesivo llegar a la irrelevancia absoluta de un modelo de cumplimiento en tales casos, pero debe reconocerse que, sobre todo por consideraciones prácticas, esa puede ser una opción legítima tanto para el legislador como, en ausencia de una decisión de este, para el juez.

\section{SÍNTESIS DE CONCLUSIONES}

De lo desarrollado precedentemente se concluye que no es racional ni justo imponer sanciones a una persona jurídica a todo evento por el solo hecho de que algún o algunos empleados de rango inferior en su estructura jerárquica hayan incurrido en una infracción legal en el desempeño de su empleo, sin hacerse cargo en absoluto de los esfuerzos desplegados seriamente por la persona jurídica (a través de sus responsables) en orden a evitar ese tipo de infracciones.

autoridad de las personas físicas mencionadas en el párrafo anterior, han podido realizar los hechos por no haberse ejercido sobre ellos el debido control atendidas las concretas circunstancias del caso".

53 En todo caso, como ya se hizo presente, desde 2015 rige en España una formulación legal prácticamente idéntica a la del Derecho italiano.

54 Montt (2011) pp. 284 ss.

55 Montt (2011) pp. 285 ss. sostiene que tampoco debería proceder la exoneración tratándose de la conducta consistente en celebrar acuerdos contrarios a la libre competencia, basándose en la práctica de la Unión Europea (por ejemplo, la decisión de la Comisión Europea en el caso Electrical and mechanical carbon and graphite products [COMP/E-2/38.359, de 3 de diciembre de 2003], en la que se desecha la invocación de un programa intensivo de cumplimiento incluso como circunstancia atenuante, véase $\$ 313$ ). Todo indica, sin embargo, que esta solo es una variante de la excepción anterior y que se asume que los llamados hard core cartels, en cuanto suelen presuponer un muy considerable grado de influencia tanto en la propia empresa como en las empresas competidoras, necesariamente han de haber sido organizados por altos ejecutivos, de modo que las eventuales dificultades puntuales para demostrar su intervención no deberían obstar a la afirmación de la responsabilidad de la persona jurídica. Pero como es obvio, aunque plausible, esta no es más que una apreciación probatoria y no un criterio material que justifique una limitación del efecto eximente de un buen programa de cumplimiento. En otras palabras, no hay nada en la naturaleza de la infracción que se oponga per se a la consideración de un posible efecto eximente de un programa de cumplimiento, sino exclusivamente una generalización probatoria mejor o peor fundada en la experiencia. 
Al contrario, es justo y racional un régimen de responsabilidad de las personas jurídicas basado en un "defecto de organización”, esto es, en una organización caracterizada por la ausencia de estructuras, procedimientos y medidas tendientes a impedir la ocurrencia del tipo de infracciones en que incurren sus empleados. Un régimen de estas características sirve como incentivo para que las personas jurídicas adopten e implementen programas serios y adecuados de prevención de hechos ilícitos (programas de cumplimiento), lo que, sin embargo, solo se logra de manera óptima y consistente si se les permite liberarse de responsabilidad cuando han desplegado los mayores esfuerzos exigibles en torno a su programa de cumplimiento. Solo bajo esa condición les vale la pena desplegar efectivamente el máximo esfuerzo y se disipan los incentivos perversos que provoca la imposibilidad de exoneración y que se vuelven contra el ideal de acatamiento de la ley (mayor exposición al castigo por la mayor disponibilidad de antecedentes incriminatorios, incentivos para la connivencia con los infractores individuales, etc.). Una somera revisión del Derecho comparado muestra una nítida tendencia internacional hacia la adopción de modelos de responsabilidad de este tipo, por las mismas razones que aquí se han expuesto.

Si bien el Derecho administrativo sancionador chileno no contempla expresamente una eximente o defensa de cumplimiento, basada en la adopción e implementación de un programa de cumplimiento serio y adecuado, tampoco se opone a su existencia, pues, en rigor, guarda silencio también sobre los presupuestos positivos de la responsabilidad de las personas jurídicas, con lo cual la determinación tanto de dichos presupuestos como de las causas que correlativamente eximen de responsabilidad queda entregada a la jurisprudencia.

Es también la jurisprudencia la que debe establecer cuál es el estándar de suficiencia en términos de adecuación y seriedad en la adopción e implementación de un modelo de cumplimiento o prevención de hechos ilícitos ${ }^{56}$. Para ello, sin embargo, ella misma debe darse primero la posibilidad de pronunciarse al respecto, admitiendo la procedencia de una eximente o defensa de cumplimiento.

\section{BIBLIOGRAFÍA CITADA}

AlCalde, Enrique (2003): Los principios generales del Derecho: su función de garantía en el Derecho público y privado chileno (Santiago, Ediciones Universidad Católica de Chile).

Alcalde, Enrique (2009): "Algunas consideraciones en torno a la identidad sustancial entre la sanción penal y la pena administrativa”, en ARAnCiBia, Jaime y MarTínez, José Ignacio (coord.), La primacía de la persona: estudios en homenaje al profesor Eduardo Soto Kloss (Santiago, LegalPublishing) pp. 795-808.

AlCALDE, Enrique (2011): "Aplicación de los principios de tipicidad, culpabilidad y proporcionalidad en la infracción administrativa", Actualidad jurídica, N² 24: pp. 69-84.

Aldunate, Eduardo (2008): Derechos fundamentales (Santiago, LegalPublishing).

ArósticA, Iván (1987): "Algunos problemas del Derecho administrativo penal", Revista de Derecho de la Universidad de Concepción, N 182: pp. 71-81.

56 Primeras orientaciones en la literatura chilena, a propósito de la Ley Nº 20.393, en PIÑA (2012) pp. 13 ss.; Artaza (2013) pp. 549 ss.; Balmaceda y Guerra (2014) pp. 31 ss. 
ArTaZA, Osvaldo (2013): "Sistemas de prevención de delitos o programas de cumplimiento. Breve descripción de las reglas técnicas de gestión del riesgo empresarial y su utilidad en sede jurídico penal", Política Criminal, Vol. 8, N 16: pp. 544-573.

Balmaceda, Gustavo y Guerra, Rodrigo (2014): Políticas de prevención de delitos en la empresa (Santiago, Thomson Reuters).

BARROS, Enrique (2006): Tratado de responsabilidad extracontractual (Santiago, Editorial Jurídica de Chile).

Bermúdez, Jorge (2014): Derecho administrativo general (Santiago, Thomson Reuters, 3a edición).

Bernasconi, Alessandro (2008): “Art. 5, Art. 6, Art. 7", en Presutti, Adonella, BernascoNI, Alessandro y Fiorio, Carlo (edit.), La responsabilità degli enti (Padova CEDAM) pp. 97-167.

Braithwaite, John (1982): "Enforced Self-Regulation: A new Strategy for Corporate Crime Control”, Michigan Law Review, Vol. 80, № 7: pp. 1466-1507.

Bucy, Pamela H. (2009): “Corporate Criminal Liability: When does It Make Sense?”, American Criminal Law Review, Vol. 46, № 4: pp. 1437-1458.

Cordero Quinzacara, Eduardo (2014): Derecho administrativo sancionador (Santiago, Thomson Reuters).

Cordero Vega, Luis (2015): Lecciones de Derecho administrativo (Santiago, Thomson Reuters).

Conso, Stefano Maria (2014): Codice della responsabilità "da reato" degli enti annotato con la giurisprudenza (Torino, Giappichelli, $2^{\circ}$ edición).

Cousiño, Luis (1992): Derecho penal chileno, T. III (Santiago, Editorial Jurídica de Chile)

Cury, Enrique (2005): Derecho penal. Parte general (Santiago, Ediciones Universidad Católica de Chile, $7^{\circ}$ edición).

Feijóo SÁnchez, Bernardo (2002): "Sobre el fundamento de las sanciones penales para personas jurídicas y empresas en el Derecho penal español y el Derecho penal peruano”, en García Cavero, Percy (coord.), La responsabilidad penal de las personas jurídicas, órganos y representantes (Lima, ARA) pp. 215-275.

FrisCH, Wolfgang (2013): "Sobre la punibilidad de personas jurídicas" (trad. Hernández), en VAN WeEzel, Alex (edit.), Humanizar y renovar el Derecho penal. Estudios en memoria de Enrique Cury (Santiago, Thomson Reuters) pp. 805-839.

Gobert, James y Punch, Maurice (2003): Rethinking Corporate Crime (London, Butterworths).

Gómez Tomillo, Manuel y Sanz Rubiales, Ínigo (2010): Derecho administrativo sancionador. Parte general (Aranzadi, Cizur Menor, $2^{\circ}$ edición).

Griffin, Stephen (2006): “Corporate Manslaughter: A Radical Reform?”, Journal of Criminal Law, Vol. 71, Parte 2: pp. 151-166.

GuZmán Dalbora, José Luis (1994): "Relaciones del Derecho penal con el derecho constitucional, y su concreción en la Constitución Política chilena”, Anuario de Filosofía Jurídica y Social, 1994: pp. 165-199.

HauschKa, Christoph (2010): Corporate Compliance. Handbuch der Haftungsvermeidung im Unternehmen (München, Beck, $2^{\circ}$ edición). 
Hernández Basualto, Héctor — Procedencia de una "eximente o defensa de cumplimiento" de las personas jurídicas en el derecho...

HernándeZ, Héctor (2007): "El régimen de la autointoxicación plena en el Derecho penal chileno: deuda pendiente con el principio de culpabilidad", Revista de Estudios de la Justicia, No 9: pp. 11-45.

Hernández, Héctor (2010): "La introducción de la responsabilidad penal de las personas jurídicas en Chile", Política Criminal, Vol. 5, N 9: pp. 207-236.

HernándeZ, Héctor (2015): “¿Derecho de las personas jurídicas a no auto-incriminarse?”, Revista de Derecho de la Pontificia Universidad Católica de Valparaiso, Vol. XLIV: pp. 217-263.

Huergo Lora, Alejandro (2007): Las sanciones administrativas (Madrid, Iustel).

Jordan, Jon (2011): “The Adequate Procedures Defense under the UK Bribery Act: A British Idea for the Foreign Corrupt Practices Act", Stanford Journal of Law, Business \& Finance, Vol. 17, $\mathrm{N}^{\circ}$ 1: pp. 25-66.

KöcK, Elisabeth (2004): “Nemo-tenetur-Grundsatz für Verbände?”, en GrafL, Christian y Medigovic, Ursula (edit.), Festschrift für Manfred Burgstaller (Wien - Graz, NW Verlag) pp. 267-280.

Künsemüller, Carlos (2001): Culpabilidad y pena (Santiago, Editorial Jurídica de Chile).

LOZANO, Blanca (1992): "La responsabilidad de la persona jurídica en el ámbito sancionador administrativo (a propósito de la STC 246/1991, de 19 de diciembre)", Revista de Administración Pública, $\mathrm{N}^{\circ}$ 129: pp. 211-239.

Matus, Jean Pierre (2013): "Sobre el valor de las certificaciones de adopción e implementación de modelos de prevención de delitos frente a la responsabilidad penal de las personas jurídicas", Revista Chilena de Derecho y Ciencias Penales, Vol. II, N²: pp. 11-22.

Mera, Jorge (1998): Derechos Humanos en el Derecho penal chileno (Santiago, ConoSur).

MontT, Santiago (2011): "Programas de compliance y responsabilidad en el Derecho de la competencia chileno", Revista de Derecho Administrativo (Perú), N 10: pp. 277-290.

Náquira, Jaime (1995): "Constitución Política y fundamento material del principio de culpabilidad", Revista Chilena de Derecho, Vol. 22, N²: pp. 189-200.

NieTo, Alejandro (2012): Derecho administrativo sancionador (Madrid, Tecnos, 5a edición).

Nieto Martín, Adán (2008 a): La responsabilidad penal de las personas jurídicas (Madrid, Iustel).

Nieto Martín, Adán (2008 b): "Responsabilidad social, gobierno corporativo y autorregulación: sus influencias en el Derecho penal de la empresa”, Política Criminal, Vol. 3, No 5, A3-5: pp. 1-18.

Ormerod, David (2005): Smith \& Hogan Criminal Law (New York, Oxford University Press, $11^{\circ}$ edición).

PiÑA, Juan Ignacio (2012): Modelos de prevención de delitos en la empresa (Santiago, Thomson Reuters).

Pollack, Barry J. (2009): "Time to Stop Living Vicariously: a Better Approach to Corporate Criminal Liability”, American Criminal Law Review, Vol. 46, № 4: pp. 1393-1416.

Rebollo Puig, Manuel (1989): Potestad sancionadora, alimentación y salud pública (Madrid, Instituto Nacional de Administración Pública). 
Ried, José Miguel (2005): “El caso Consorcio 2 - Banco de Chile: información privilegiada y potestad sancionatoria de la administración”, Sentencias Destacadas (Libertad y Desarrollo), 2005: pp. 31-44.

Rodríguez Collao, Luis y De la Fuente, Felipe (1989): "El principio de culpabilidad en la Constitución de 1980", Revista de Derecho de la Universidad Católica de Valparaíso, Vol. XIII: pp. 125-153.

Rogall, Klaus (2014), “\$ 30, $\$ 130 ”$ en SEnge, Lothar (edit.), Karlsruher Kommentar zum Gesetz über Ordnungswidrigkeiten (München, Beck, $4^{\circ}$ edición) pp. 489-573, 17461789.

Schünemann, Bernd (1995): "La punibilidad de las personas jurídicas desde la perspectiva europea" (trad. Peñaranda Ramos y Pérez Manzano), en AA. VV., Hacia un Derecho penal económico europeo. Jornadas en honor del Prof. Klaus Tiedemann (Madrid, Boletín Oficial del Estado) pp. 565-600.

Silva Sánchez, Jesús María (2016): "La eximente de 'modelos de prevención de delitos'. Fundamento y bases para una dogmática”, en CárdenAs, Claudia y FERDMAN, Jorge (coord.), El Derecho penal como teoría y como práctica. Libro en homenaje a Alfredo Etcheberry Orthusteguy (Santiago, Thomson Reuters) pp. 869-899.

Simester, AP, Spencer, JR, Sullivan, GR y Virgo, GJ (2013): Simester and Sullivan's Criminal Law. Theory and Doctrine (Hart, Oxford - Portland, 5a edición).

Soто, Miguel (1999): "Una jurisprudencia histórica: hacia el reconocimiento del 'principio de culpabilidad' en el Derecho penal chileno", Revista de Derecho de la Universidad Finis Terrae, No 3: pp. 233-253.

STEININGER, Einhard (2006): Verbandsverantwortlichkeitsgesetz. Kommentar (Wien, Linde).

Strader, J. Kelly (2011): Understanding White Collar Crime (New Providence - San Francisco, LexisNexis, $3^{\mathrm{a}}$ edición).

Stratenwerth, Günter y Wohlers, Wolfgang (2013): Schweizerisches Strafgesetzbuch. Handkommentar (Bern, Stämpfli, $3^{a}$ edición).

Tiedemann, Klaus (1988): "Die 'Bebußung' von Unternehmen nach dem 2. Gesetz zur Bekämpfung der Wirtschaftskriminalität”, Neue Juristische Wochenschrift, 1988: pp. 11691174 .

VALDÉs, Domingo (2006): Libre competencia y monopolio (Santiago, Editorial Jurídica de Chile).

Vergara, Alejandro (2004 a): Derecho Eléctrico (Santiago, Editorial Jurídica de Chile).

Vergara, Alejandro (2004 b): "Esquema de los principios del Derecho administrativo sancionador", Revista de Derecho de la Universidad Católica del Norte, año 11, No 2: pp. 137-147.

Weissmann, Andrew y Newman, David (2007): "Rethinking Criminal Corporate Liability", Indiana Law Journal, Vol. 82, No 2: pp. 411-452.

Yeung, Karen (2004): Securing Compliance (Oxford - Portland, Hart). 


\section{JURISPRUDENCIA CITADA}

Tribunal Constitucional de Chile

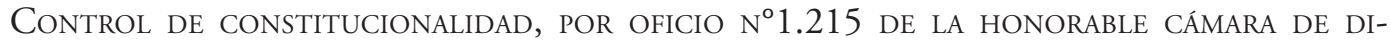

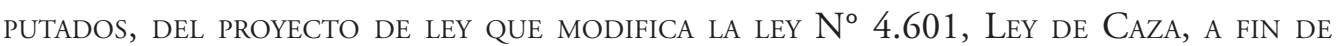
proteger la fauna (1996): Tribunal Constitucional chileno, Rol No 244, 26 de agosto de 1996.

REQUERIMIENTO DE INAPLICABILIDAD POR INCONSTITUCIONALIDAD DE IBEROAMERICANA DE ENERgÍa Ibener S.A., Respecto de Diversas disposiciones de la Ley Orgánica de la Superintendencia de Electricidad y Combustibles y del artículo $81 \mathrm{~N}^{\circ} 1$ del DFL Nº1 de 1982 del Ministerio de Minería, en la Causa Caratulada "Iberoamericana de Energía Ibener S.A. con Superintendencia de Electricidad y Combustibles” (2006): Tribunal Constitucional chileno, Rol No 480, de 27 de julio de 2006.

Requerimiento de inaplicabilidad por inconstitucionalidad de Mauricio Ramírez Go-

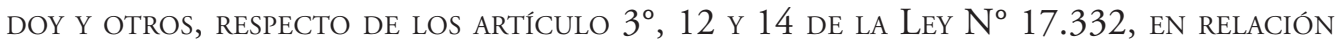
con diversas causas seguidas ante el Séptimo Juzgado del Trabajo de Santiago (2007): Tribunal Constitucional chileno, Rol No 519, 5 de junio de 2007.

REQUERIMIENTO DE INAPLICABILIDAD POR InCONSTITUCIONALIDAD DE R.O.L, E.H.S Y E.O., y de J.C.C.C., Respecto del inciso primero del artículo 317 del Código Penal, en Relación CON SU artículo 315, en los autos RUC 0800102576-8 del Tribunal de Garantía de San Bernardo (2010): Tribunal Constitucional chileno, Rol Nº 1584, 17 de junio de 2010.

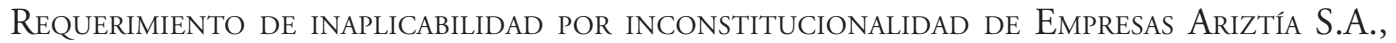
respecto del artículo 29 del Decreto Ley N²11 de 1973, sobre Defensa de la Li-

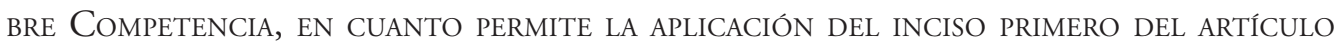
385 del Código de Procedimiento Civil en la causa seguida ante el Tribunal de Defensa de la Libre Competencia bajo el Rol C No 236-11 (2013): Tribunal Constitucional chileno Rol No 2381, 20 de agosto de 2013.

Tribunal de Defensa de la Libre Competencia de Chile.

FNE contra Compañáa Chilena de Tabacos S.A. (2011): Sentencia 115, de 17 de noviembre de 2011, Rol N¹96-09.

FNE CONTRA Agrícola Agrosuper S.A. y otros (2014): Sentencia 139, de 25 de septiembre de 2014, Rol No 236-11.

FNE Contra la Asociación GRemial de Ginecólogos Obstetras de la Provincia De NuUble Y OTROS (2015): Sentencia 145, de 1 de abril de 2015, Rol N² 265-13.

FNE contra Asfaltos Chilenos S.A. y otros (2015): Sentencia 148, de 23 de diciembre de 2015, Rol N²80-14.

FNE CONTRA CADENAS DE FARMACIAS (2009): Resolución de 13 de abril de 2009, Rol № 184-08

Tribunal Constitucional de España

STC 246/1991, de 19 de diciembre de 1991

Comisión Europea 
Decisión Electrical and mechanical carbon and graphite products, COMP/E-2/38.359, de 3 de diciembre de 2003.

\section{NORMAS CITADAS}

Alemania

Gesetz über Ordnungswidrigkeiten (Ordnungswidrigkeitengesetz - OWiG) (24/5/1968).

Austria

Verbandsverantwortlichkeitsgesetz (VbVG) (23/12/2005).

Chile

LEY $N^{\circ} 20.393$ (2/12/2009), establece la responsabilidad penal de las personas jurídicas en los delitos de lavado de activos, financiamiento del terrorismo y delitos de cohecho que indica.

Superintendencia de Valores y Seguros: Norma de Carácter General N ${ }^{\circ} 309$ (20/6/2011), sobre principios de gobierno corporativo y sistemas de gestión de riesgo y control interno.

Superintendencia de Valores y Seguros: Norma de Carácter General No 408 (31/3/2016), modifica NCG Nº 309 .

España

LEY 30/1992, de 26 de noviembre, de Régimen Jurídico de las Administraciones Públicas y del Procedimiento Administrativo Común

LeY 40/2015, de 1 de octubre, de Régimen Jurídico del Sector Público.

Ley Orgánica 10/1995, de 23 de noviembre, del Código Penal.

Estados Unidos

Sentencing Guidelines for Organizations (1/11/1991).

Foreign Corrupt Practices Act (FCPA) (19/12/1977).

Italia

Decreto Legislativo n. 231 (8/6/2001), Disciplina della responsabilità amministrativa delle persone giuridiche, delle società e delle associazioni anche prive di personalità giuridica, a norma dell'articolo 11 della legge 29 settembre 2000, n. 300.

Reino Unido

Corporate Manslaughter and Corporate Homicide Act 2007 (26/7/2007).

Bribery Act 2010 (8/4/2010).

Suiza

Schweizerisches Strafgesetzbuch (21/12/1937). 